\title{
Breast Cancer Surveillance Consortium
}

National Cancer Institute

\section{Source}

National Cancer Institute. Breast Cancer Surveillance Consortium. NCI Thesaurus. Code C19661.

Comprised of nine academic and public institutions and private organizations. The consortium's three main objectives are: 1) To better understand breast cancer screening practices in the United States by assessing the accuracy, cost, and quality of screening programs and the relation of these practices to changes in breast cancer mortality and other outcomes, such as survival; 2) To foster collaborative research among Consortium participants that examines issues such as regional and health care system differences in the provision of screening and follow-up evaluations; and 3) To provide a foundation for conducting clinical and basic science research, especially basic research on biological mechanisms, that can improve our understanding of the natural history of breast cancer. 